\title{
A Case of Venlafaxine-Induced Interstitial Lung Disease
}

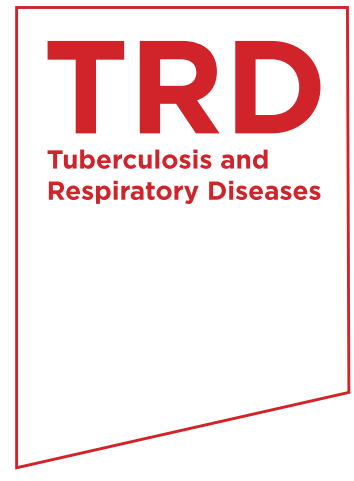

\author{
Serim Oh, M.D. ${ }^{1}$, Seung-Ick Cha, M.D. ${ }^{1}$, Hyera Kim, M.D. ${ }^{1}$, Minjung Kim, M.D. ${ }^{1}$, Sun Ha Choi, M.D. ${ }^{1}$, \\ Hyewon Seo, M.D. ${ }^{1}$ and Tae-In Park, M.D. ${ }^{2}$
}

Departments of ${ }^{1}$ Internal Medicine and ${ }^{2}$ Pathology, Kyungpook National University School of Medicine, Daegu, Korea

A patient treated with venlafaxine for major depression developed an interstitial lung disease (ILD) with the characteristic clinical, radiological and pathological features of chronic hypersensitivity pneumonitis. A high resolution computed tomography scan demonstrated ground glass opacity, mosaic perfusion with air-trapping and traction bronchiectasis in both lungs. The pathological findings were consistent with a nonspecific interstitial pneumonia pattern. Clinical and radiological improvements were noted after the discontinuation of venlafaxine and the administration of a corticosteroid. This report provides further evidence that the anti-depressant venlafaxine can cause ILD.

Keywords: Hypersensitivity; Pneumonia; Lung Disease, Interstitial; Venlafaxine

\section{Introduction}

Venlafaxine, a drug that inhibits the uptake of both serotonin and norepinephrine, is an effective antidepressant with a favorable side effect profile ${ }^{1-3}$. The common adverse effects of venlafaxine include anorexia, xerostomia, diarrhea, insomnia, nausea, nervousness, sleepiness, sweating, hypertension, and arrhythmia ${ }^{2,4}$. Pulmonary toxicity of venlafaxine is known to be very rare, although a few cases of venlafaxine-induced asthma ${ }^{5}$, eosinophilic pneumonia ${ }^{1,6,7}$, and interstitial pneumonitis $^{2,8}$ have been reported. This report describes a recently discovered case of venlafaxine-induced interstitial lung disease (ILD).

\section{Address for correspondence: Seung-Ick Cha, M.D.}

Department of Internal Medicine, Kyungpook National University

Hospital, 130 Dongdeok-ro, Jung-gu, Daegu 700-721, Korea

Phone: 82-53-200-6412, Fax: 82-53-426-2046

E-mail: sicha@knu.ac.kr

Received: Mar. 20, 2014

Revised: Apr. 21, 2014

Accepted: Apr. 29, 2014

(a) It is identical to the Creative Commons Attribution Non-Commercial License (http://creativecommons.org/licenses/by-nc/3.0/).

Copyright (c) 2014

The Korean Academy of Tuberculosis and Respiratory Diseases.

All rights reserved.

\section{Case Report}

A 68-year-old woman was admitted to a local hospital three months prior to presentation at our institution (Kyungpook National University Hospital [KNUH]]), with a three-month history of a non-productive cough. The patient underwent a surgical lung biopsy, and was diagnosed with "interstitial lung fibrosis." At the local hospital, the patient was prescribed oral $\mathrm{N}$-acetylcysteine for three months. Subsequently, she was referred and admitted to the KNUH with a persistent cough and progressive dyspnea. At admission, the patient also complained of anorexia and general weakness. She had never smoked, had no prior respiratory illness, and no significant environmental or occupational exposures were noted. However, 14 years prior to this admission, she had been diagnosed with a depressive disorder, and had received anti-depression medication at several clinics and hospitals. Twenty-one months prior to this admission, she had started her current regime of psychiatric medication at a clinic, which included venlafaxine, lorazepam, alprazolam, and flunitrazepam. Her medication history was reviewed for agents known to cause drug-induced ILD, and subsequently, it was determined that venlafaxine was the only prescribed drug possibly associated with druginduced ILD. When first prescribed, venlafaxine was administered at $150 \mathrm{mg} / \mathrm{day}$, but this dosage was later increased to $225 \mathrm{mg} /$ day, nine months before admission to KNUH.

On admission, the patient was afebrile, and her blood pressure, heart rate, respiratory rate, and body temperature were 
129/70 mm Hg, 78 beats per minute, 20 breaths per minute, and $36.5^{\circ} \mathrm{C}$, respectively. She had no clubbing, but auscultation revealed crackles in both whole lung fields. Arterial blood gas analysis on room air yielded the following results: $\mathrm{pH}, 7.47$; partial pressure of oxygen $\left(\mathrm{PaO}_{2}\right), 66 \mathrm{~mm} \mathrm{Hg}$; partial pressure of carbon dioxide $\left(\mathrm{PaCO}_{2}\right), 36 \mathrm{~mm} \mathrm{Hg}$; and bicarbonate, 26 $\mathrm{mmol} / \mathrm{L}$. Leukocytosis was not apparent in peripheral blood (white blood cell count, $6,530 / \mu \mathrm{L}$ ), and C-reactive protein was within the normal range $(0.32 \mathrm{mg} / \mathrm{dL})$. A human immunodeficiency virus test yielded negative results, and serologic tests for connective tissue diseases, which included antinuclear antibody, rheumatoid factor, and anti-cyclic citrullinated peptide antibody, also yielded negative results. A chest radiograph revealed diffuse reticular opacities in both lungs (Figure 1A), and a high-resolution computed tomography (HRCT) scan revealed patchy ground glass opacities, mosaic perfusion, and traction bronchiectasis in both lungs (Figure 1B, C). A pulmonary function test confirmed the presence of a moderate restrictive lung defect and gas exchange impairment. Forced vital capacity (FVC) was $1.52 \mathrm{~L}$ (60\% predicted), forced expiratory volume in one second $\left(\mathrm{FEV}_{1}\right)$ was $1.19 \mathrm{~L}$ (66\% predicted), $\mathrm{FEV}_{1} / \mathrm{FVC}$, was $78 \%$, diffusing capacity for carbon monoxide was $11.2 \mathrm{~mL} / \mathrm{mm} \mathrm{Hg} / \mathrm{min}$ (61\% predicted), and total lung capacity was $3.29 \mathrm{~L}$ (78\% predicted). Analysis of bronchoalveolar lavage (BAL) fluid showed mild lymphocytosis. The BAL fluid cell count was $4.5 \times 10^{5} / \mathrm{mL}$, and included $17 \%$ lympho-
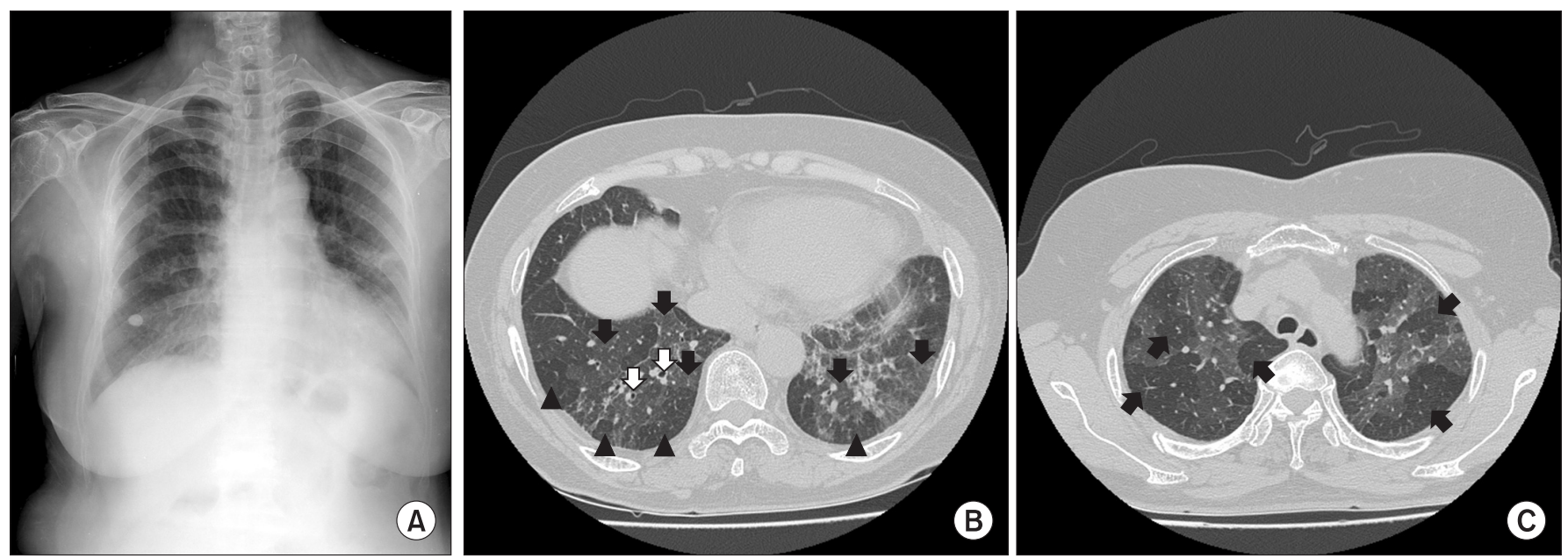

Figure 1. (A) The chest radiograph demonstrates diffuse reticulonodular opacities in both lungs. (B) A high resolution computed tomography (HRCT) scan reveals diffuse patchy ground glass opacity (black arrows), mosaic perfusion (black arrowheads) and traction bronchiectasis (white arrows) in both lungs. (C) Air-trapping (black arrows) is noted in an expiratory view of the HRCT scan.
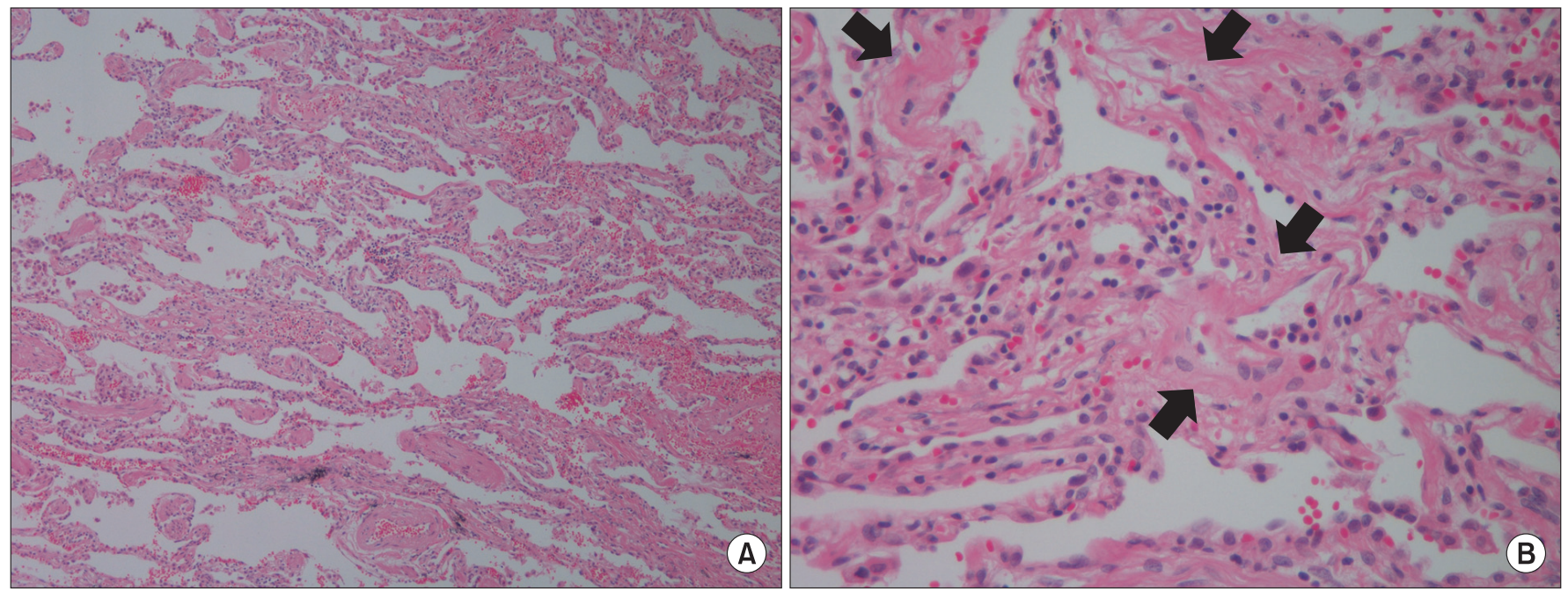

Figure 2. A surgical lung biopsy showed interstitial infiltrations of lymphocytes and plasma cells and a focal fibrosis with collagen fiber deposition (arrows) (A, H\&E stain, $\times 100$; B, H\&E stain, $\times 400$ ). 
cytes, 3\% eosinophils, and $80 \%$ macrophages. A lymphocyte subset analysis of BAL fluid conducted using flow cytometry revealed $84 \%$ T cells, $64 \%$ CD4+ cells, $21 \%$ CD8+ cells, a CD4/ CD8 ratio of three, $0.9 \%$ B cells, $13 \%$ NK cells. A pathologist (T.I.P.) reviewed the pathology slides, and identified interstitial infiltrates of lymphocytes and plasma cells, and focal fibrosis with collagen fiber deposition, which were consistent with a nonspecific interstitial pneumonia (NSIP). However, no fibroblastic foci or granulomas were observed (Figure 2).

Based on analytical results, venlafaxine-induced ILD was suspected. Thus, venlafaxine was discontinued, and oral prednisolone $(0.5 \mathrm{mg} / \mathrm{kg} /$ day $)$ was administered. After starting prednisolone, the cough and dyspnea slowly improved, and after four months, radiological findings were found to have improved by follow-up computed tomography (CT).

\section{Discussion}

This case provides further evidence that venlafaxine can cause drug-induced ILD. Accordingly, we advise that like clozapine, a selective serotonin reuptake inhibitor ${ }^{9}$, and fluoxetine, an atypical antipsychotic ${ }^{10}$, venlafaxine should be considered an anti-psychiatric drug that can cause drug-induced ILD. Currently, the incidences of venlafaxine-induced lung toxicity and ILD are not known. However, given the widespread use of venlafaxine for psychiatric indications, including major depressive disorders, venlafaxine-induced ILD appears to be rare ${ }^{2}$. A direct toxic effect on lung tissue and hypersensitivity reactions may be involved in venlafaxine-induced $\mathrm{ILD}^{2}$. However, like lung toxicities caused by other drugs, the mechanism whereby venlafaxine might trigger interstitial pneumonitis remains unknown ${ }^{2}$.

To establish that a drug causes a disease, several criteria must be fulfilled, that is, a temporal relation between drug commencement and disease onset, the clinical manifestations of disease characteristics, and clinical improvement after drug discontinuation ${ }^{8}$. In the present case, our patient developed respiratory symptoms, including a persistent cough, 21 months after she started taking venlafaxine, and three months after venlafaxine was increased to $225 \mathrm{mg} /$ day, which supports the temporal relation between drug commencement and the development of respiratory symptoms.

As mentioned above, previously reported cases of pulmonary toxicities associated with venlafaxine include asthma ${ }^{5}$, eosinophilic pneumonia ${ }^{1,6,7}$, and interstitial pneumonitis ${ }^{2,8,11}$. All previously reported cases with interstitial pneumonitis exhibited radiological and pathological features consistent with hypersensitivity pneumonitis (HP). Similarly, in the present case, HRCT demonstrated bilateral mosaic perfusion with airtrapping, a characteristic CT finding of $\mathrm{HP}^{12}$, although poorlydefined centrilobular nodules were not apparent. The NSIP pattern is considered one of the pathological findings of HP, although bronchiolocentric inflammation and poorly formed granulomas were not observed. Our analysis of BAL fluid indicated mild lymphocytosis with an increased CD4/CD8 ratio rather than marked lymphocytosis with a decreased CD4/ CD8 ratio, which is typical of HP. However, these findings concur with the fact that patients with chronic HP exhibit lower BAL lymphocytosis and increased levels of CD8+ T lymphocytes in BAL fluid ${ }^{13}$, which suggests that the presented case was of a more chronic form than previously reported cases of venlafaxine-induced interstitial pneumonitis ${ }^{2,8,11}$. Accordingly, this is the first report of venlafaxine-induced ILD presenting as a chronic form similar to chronic HP. Finally, after venlafaxine was discontinued and corticosteroid administered, clinical manifestations and radiological findings improved, which fulfilled the last criterion of drug-induced toxicity. In addition, to relate venlafaxine to drug-induced lung toxicity in the present case, we used the Naranjo algorithm to score adverse drug reaction probability. We obtained a score of six, indicating the "probable" category ${ }^{14}$.

In conclusion, venlafaxine is an antidepressant that can cause drug-induced ILD, which is characterized by the clinical, radiological, and pathological features of HP. This is the first report to describe venlafaxine-induced ILD with chronic HP-like manifestations. Clinicians need to be aware that venlafaxine can cause drug-induced ILD in psychiatric patients.

\section{Conflicts of Interest}

No potential conflict of interest relevant to this article was reported.

\section{References}

1. Paparrigopoulos T, Tzavellas E, Karaiskos D, Ilias I, Liappas I. Acute eosinophilic pneumonia after venlafaxine overdose. J Clin Psychopharmacol 2011;31:258-9.

2. Turner RC, Nelson JE, Roberts BT, Gillam DM. Venlafaxine-associated interstitial pneumonitis. Pharmacotherapy 2005;25: 626-9.

3. Feighner JP. The role of venlafaxine in rational antidepressant therapy. J Clin Psychiatry 1994;55 Suppl A:62-8.

4. Andrews JM, Ninan PT, Nemeroff CB. Venlafaxine: a novel antidepressant that has a dual mechanism of action. Depression 1996;4:48-56.

5. Melien O, Skaali T, Myhr K, Brors O. Venlafaxine and asthma. Nord J Psychiatry 2005;59:538-40.

6. Tsigkaropoulou E, Hatzilia D, Rizos E, Christodoulou C, Loukides S, Papiris S, et al. Venlafaxine-induced acute eosinophilic pneumonia. Gen Hosp Psychiatry 2011;33:411.e7-9.

7. Fleisch MC, Blauer F, Gubler JG, Kuhn M, Scherer TA. Eosinophilic pneumonia and respiratory failure associated with 
venlafaxine treatment. Eur Respir J 2000;15:205-8.

8. Drent M, Singh S, Gorgels AP, Hansell DM, Bekers O, Nicholson AG, et al. Drug-induced pneumonitis and heart failure simultaneously associated with venlafaxine. Am J Respir Crit Care Med 2003;167:958-61.

9. Arias SA, Cohen P, Kwon JS. Clozapine-induced lymphocytic alveolitis. Am J Psychiatry 2011;168:210-1.

10. Gonzalez-Rothi RJ, Zander DS, Ros PR. Fluoxetine hydrochloride (Prozac)-induced pulmonary disease. Chest 1995; 107:1763-5.

11. Borderias Clau L, Marigil Gomez MA, Val Adan P, Marcen Letosa M, Biescas Lopez R, Garrapiz Lopez FJ. Hypersensi- tivity pneumonitis due to venlafaxine. Arch Bronconeumol 2008;44:571-3.

12. Patel RA, Sellami D, Gotway MB, Golden JA, Webb WR. Hypersensitivity pneumonitis: patterns on high-resolution CT. J Comput Assist Tomogr 2000;24:965-70.

13. Barrera L, Mendoza F, Zuniga J, Estrada A, Zamora AC, Melendro EI, et al. Functional diversity of T-cell subpopulations in subacute and chronic hypersensitivity pneumonitis. Am J Respir Crit Care Med 2008;177:44-55.

14. Naranjo CA, Busto U, Sellers EM, Sandor P, Ruiz I, Roberts EA, et al. A method for estimating the probability of adverse drug reactions. Clin Pharmacol Ther 1981;30:239-45. 